\title{
Intrasession repeatability of refractive and ocular aberrometric measurements obtained using a multidiagnostic device in healthy eyes
}

This article was published in the following Dove Press journal:

Clinical Optometry

4 May 2017

Number of times this article has been viewed

\author{
David P Piñero' \\ Alberto López-Navarro² \\ Inmaculada Cabezos' \\ Dolores de Fez' \\ María T Caballero' \\ Vicent J Camps' \\ 'Group of Optics and Visual \\ Perception, Department of Optics, \\ Pharmacology and Anatomy, \\ University of Alicante, ${ }^{2}$ Optometry \\ Clinic, Prevention Service of the \\ University of Alicante, Alicante, Spain
}

Correspondence: David P Piñero Department of Optics, Pharmacology and Anatomy, University of Alicante, Crta San Vicente del Raspeig s/n 03690, San Vicente del Raspeig, Alicante, Spain Tel +34965903500

Fax +34965903464

Email david.pinyero@ua.es
Purpose: To evaluate the intrasession repeatability of refractive and ocular aberrometric measurements obtained using a new multidiagnostic device in healthy eyes.

Patients and methods: A total of 107 eyes of 107 patients, age ranging from 23 to 65 years, were enrolled in this study. A complete eye examination was performed in all eyes, including an ocular examination using the VX120 system. Three consecutive measurements were obtained using this device to assess the intrasession repeatability of different refractive and ocular aberrometric parameters. The within-subject standard deviation $\left(\mathrm{S}_{\mathrm{w}}\right)$, intrasubject precision $\left(1.96 \times \mathrm{S}_{\mathrm{w}}\right)$, and intraclass correlation coefficient (ICC) were calculated.

Results: $\mathrm{S}_{\mathrm{w}}$ and intrasubject precision for refractive data were below 0.12 and $0.20 \mathrm{D}$, respectively, in all cases. The ICC ranged from 0.947 for the $\mathrm{J}_{45}$ power vector component to 0.997 for the sphere. Concerning aberrometric measurements $\mathrm{S}_{\mathrm{w}}$ and intrasubject precision values were below $0.05 \mu \mathrm{m}$ and $0.10 \mu \mathrm{m}$, respectively. Likewise, the ICC ranged from 0.805 for the quadrafoil root mean square to 0.954 for the primary spherical aberration. Poor correlations were found between most of the refractive parameters and their $\mathrm{S}_{\mathrm{w}}(-0.033 \leq r \leq 0.053, p \geq 0.064)$. Moderate and significant positive correlations were found between the magnitude of the aberrometric parameters evaluated and their $\mathrm{S}_{\mathrm{w}}(r \geq 0.446, p<0.001)$.

Conclusion: The new multidiagnostic device evaluated is able to provide consistent measurements of refraction and ocular aberrations in healthy eyes. Future studies should confirm if this consistency is also observed in highly aberrated eyes.

Keywords: ocular aberrations, refraction, Scheimpflug imaging, VX120 system, intrasession repeatability

\section{Introduction}

Multidiagnostic devices based on corneal and anterior segment imaging techniques have become a crucial tool in the clinical practice of ophthalmology and optometry, with a great variety of applications, such as corneal curvature and pachymetric analysis, detection of ectatic corneal conditions, anatomical study of the anterior segment prior to phakic intraocular lens implantation, and densitometric analysis of the crystalline lens. ${ }^{1}$ One of the main features of these devices is the clinical characterization of the ocular optics, providing a measurement of objective refraction and ocular aberrations. ${ }^{2,3}$ Some studies have evaluated the consistency of refractive and aberrometric measurements provided by different models of devices measuring ocular refraction and aberrations. ${ }^{2-9}$ Nonconsistent aberrometric measurements in the clinical practice can lead to incorrect clinical decisions. In refractive surgery, it has been shown that 
the variability of aberrometric measurements can be a major limitation of a truly successful wavefront-guided excimer laser procedure. ${ }^{9}$ Specifically, surgeons should consider treating higher order aberration (HOA) magnitudes that are more than the intrasession repeatability values $(2.77$ times of the intrasession standard deviation). ${ }^{9}$ Recently, a new multidiagnostic platform has been developed that provides automatic measurements of corneal topography, corneal, internal and ocular aberrations, pachymetry, anterior chamber depth, iridocorneal angle, pupil diameter under different luminance conditions, and intraocular pressure (IOP), which is the VX120 system (Visionix-Luneau Technologies, Chartres, France). To this date, there are no scientific studies evaluating the consistency of any type of measurements provided by this device. Only Shneor et a ${ }^{10}$ evaluated the consistency of refractive measurements provided by a previous version of the aberrometer included in the VX120 multidiagnostic system. The aim of the present study was to evaluate the intrasession repeatability of refractive and ocular aberrometric measurements obtained using this multidiagnostic device in a sample of normal healthy eyes.

\section{Patients and methods}

\section{Patients}

A total of 107 healthy eyes of 107 patients with age ranging from 23 to 65 years were included in this study. We used the same sample previously evaluated in a study conducted by our research group to analyze the consistency of corneal topographic measurements provided by the VX120 system. ${ }^{11}$ All subjects were selected randomly from patients attending the Optometric Clinic of the University of Alicante, where this investigation was developed. Only 1 eye from each subject was chosen randomly for the study according to a random number sequence (dichotomic sequence, 0 and 1) in order to avoid the potential interference of the correlation that often exists between the 2 eyes of the same person. Inclusion criteria were age of $>18$ years, refraction error between +5.00 and $-10.00 \mathrm{D}$, and eyes without pathology. The exclusion criteria were previous ocular surgery, glaucoma, $<18$ complete consecutive Placido rings projected on the cornea and, therefore, considered for the corneal analysis, pseudophakia, corneal ectatic diseases, and any other type of pathological condition of the eye. All patients were informed previously about the study and signed an informed consent document in accordance with the tenets of the Declaration of Helsinki. An approval for the performance of the study was obtained from the ethics committee of the University of Alicante (Spain).

\section{Ocular examination}

A complete eye examination was performed in all cases that included measurement of uncorrected visual acuity and objective refraction, air tonometry and corneal topographic and anterior segment analysis with the multidiagnostic device VX120 (VX120 system, Visionix-Luneau Technologies). All tests were performed by a single experienced examiner (ALN). In all cases, 3 consecutive measurements of objective refraction and ocular aberrations were obtained using the multidiagnostic system in order to assess their intrasession consistency. Aberrometric data were calculated by the device for a $5 \mathrm{~mm}$ pupil aperture by default and, therefore, included in the analysis this way.

\section{VXI20 system}

The VX120 system is a multidiagnostic platform that combines a Hartmann-Shack aberrometer, a Placido disk corneal topographer, a Scheimpflug imaging-based system, and an air tonometer. The Hartmann-Shack aberrometer of the VX120 system measures 1,500 points in 0.2 seconds in an area ranging from 2.0 to $7.0 \mathrm{~mm}$ of diameter. The Scheimpflug imaging-based system uses monochromatic blue light of $455 \mathrm{~nm}$ to obtain pachymetric measurements with a resolution of $\pm 1 \mu \mathrm{m}$ and iridocorneal angle measurements with a resolution of $\pm 1^{\circ}$. The Placido disk system projects 24 rings on the corneal surface, measuring $>100,000$ points. The combination in 1 device of all these technologies allows obtaining tangential and axial curvature data of the anterior corneal surface, a biometric estimation of various anterior segment structures, measurement of corneal, internal, and ocular wavefront aberrations, visual quality simulations, corneal pachymetry maps, and IOP measurements.

\section{Statistical analysis}

The statistical analysis was performed using the software SPSS version 15.0 for Windows (SPSS, Chicago, IL, USA). Normality of all data distributions was confirmed by means of the Kolmogorov-Smirnov test. Then, parametric statistics was always applied. Intrasession repeatability for each refractive and aberrometric parameter evaluated was assessed by means of the following statistical variables: the within-subject standard deviation $\left(\mathrm{S}_{\mathrm{w}}\right)$ of the 3 consecutive measurements, intrasubject precision $\left(1.96 \times \mathrm{S}_{\mathrm{w}}\right)$, and the intraclass correlation coefficient (ICC). The within-subject standard deviation $\left(\mathrm{S}_{\mathrm{w}}\right)$ is a simple way of estimating the size of the measurement error. The intraobserver precision was defined as $\left( \pm 1.96 \times \mathrm{S}_{\mathrm{w}}\right)$ and this parameter indicates how large is the range of error of the repeated measurements for $95 \%$ of observations. Finally, 
the ICC is an analysis of variance-based type of correlation that measures the relative homogeneity within groups (between the repeated measurements) in ratio to the total variation. The ICC will approach 1.0 when there is no variance within repeated measurements, indicating that total variation in measurements is due solely to variability in the parameter being measured. Furthermore, Pearson correlation coefficients were used to assess the correlation between the different parameters evaluated. All statistical tests were 2-tailed, and $p$-values $<0.05$ were considered statistically significant.

\section{Refraction notation}

The spherocylindrical refractions obtained were converted to vectorial notation using the power vector method described by Thibos and Horner. ${ }^{12}$ Using this procedure, any spherocylindrical refractive error can be expressed by 3 dioptric powers: $\mathrm{M}, \mathrm{J}_{0}$, and $\mathrm{J}_{45}, \mathrm{M}$ being a spherical lens equal to the spherical equivalent of the given refractive error, and $\mathrm{J}_{0}$ and $\mathrm{J}_{45} 2$ Jackson crossed cylinders equivalent to the conventional cylinder. These numbers are the coordinates of a point in a 3-dimensional dioptric space $\left(\mathrm{M}, \mathrm{J}_{0}\right.$, and $\left.\mathrm{J}_{45}\right)$. The length of this vector is a measure of the overall blurring strength $B$ of a spherocylindrical refractive error.

According to the power vector method, manifest refractions in conventional script notation ( $\mathrm{S}$ [sphere], $\mathrm{C}$ [cylinder] $\times \phi$ [axis]) were converted to power vector coordinates and overall blurring strength (B) by the following formulae: $\mathrm{M}$ $=\mathrm{S}+\mathrm{C} / 2 ; \mathrm{J}_{0}=(-\mathrm{C} / 2) \cos (2 \phi) ; \mathrm{J}_{45}=(-\mathrm{C} / 2) \sin (2 \phi) ;$ and $\mathrm{B}=\left(\mathrm{M}^{2}+\mathrm{J}_{0}{ }^{2}+\mathrm{J}_{45}{ }^{2}\right)^{1 / 2}$.

\section{Results}

The study involved 107 eyes of 107 subjects with a mean age of 47.8 years (ranging from 23 to 65 years). A total of $45.8 \%$ (49) subjects were male and $54.2 \%$ (58) were female. Table 1 summarizes the outcomes of the intrasession repeatability analysis for all refractive measurements. The $\mathrm{S}_{\mathrm{w}}$ and intrasubject precision for refractive data were below 0.12 and $0.20 \mathrm{D}$ in all cases. The ICC ranged from 0.947 for the $\mathrm{J}_{45}$ power vector component to 0.997 for the sphere. Concerning the aberrometric measurements (Table 2), $\mathrm{S}_{\mathrm{w}}$ and intrasubject precision values were below 0.05 and $0.10 \mu \mathrm{m}$, respectively. Likewise, the ICC ranged from 0.805 for the quadrafoil root mean square (RMS) to 0.954 for the Zernike term corresponding to the primary spherical aberration.

Table 3 displays the coefficients of correlation of all relationships between the magnitudes of the different refractive and aberrometric parameters evaluated and their associated $\mathrm{S}_{\mathrm{w}}$. As shown, no statistically significant correlations of
Table I Summary of the intrasession repeatability outcomes for the refractive measurements obtained by means of the VXI20 system

\begin{tabular}{|c|c|c|c|c|}
\hline $\begin{array}{l}\text { Refractive } \\
\text { parameter }\end{array}$ & $\begin{array}{l}\text { Overall mean (SD) } \\
\text { Overall median } \\
\text { (range) }\end{array}$ & $\mathbf{S}_{w}\left({ }^{\circ}\right)$ & $\operatorname{Pr}\left({ }^{\circ}\right)$ & $\begin{array}{l}\text { ICC (range } \\
95 \% \mathrm{Cl})\end{array}$ \\
\hline Sphe & $\begin{array}{l}-0.43(2.02) \\
0.00(-7.00 \text { to } 6.00)\end{array}$ & 0.05 & 011 & $\begin{array}{l}0.997(0.996 \\
\text { to } 0.998)\end{array}$ \\
\hline Cylinder (D) & $\begin{array}{l}-0.40(0.75) \\
0.00(-4.00 \text { to } 0.00)\end{array}$ & 0.10 & 0.19 & $\begin{array}{l}0.959(0.944 \\
\text { to } 0.971)\end{array}$ \\
\hline $\mathrm{J}_{0}(\mathrm{D})$ & $\begin{array}{l}0.06(0.35) \\
0.00(-0.99 \text { to } 1.85)\end{array}$ & 0.04 & 0.07 & $\begin{array}{l}0.975(0.965 \\
\text { to } 0.982)\end{array}$ \\
\hline $\mathrm{J}_{45}(\mathrm{D})$ & $\begin{array}{l}0.01(0.23) \\
0.00(-1.00 \text { to } 0.8 I)\end{array}$ & 0.03 & 0.07 & $\begin{array}{l}0.947(0.926 \\
\text { to } 0.962)\end{array}$ \\
\hline B & $\begin{array}{l}1.40(1.65) \\
1.00(0.00 \text { to } 7.34)\end{array}$ & 0.09 & 0.18 & $\begin{array}{l}0.995(0.993 \\
\text { to } 0.996)\end{array}$ \\
\hline
\end{tabular}

Abbreviations: $S_{w}$, within-subject standard deviation; $J_{0}$ and $J_{45}$, power vector components; $B$, overall blurring strength; $\mathrm{Pr}$, intrasession precision $1.96 \times \mathrm{S}_{\mathrm{w}} ; \mathrm{SD}$, standard deviation; ICC, intraclass correlation coefficient.

Table 2 Summary of the intrasession repeatability outcomes for the aberrometric measurements obtained by means of the VXI20 system

\begin{tabular}{|c|c|c|c|c|}
\hline $\begin{array}{l}\text { Aberrometric } \\
\text { parameter }\end{array}$ & $\begin{array}{l}\text { Overall mean (SD) } \\
\text { Overall median } \\
\text { (range) }\end{array}$ & $\mathbf{S}_{w}\left({ }^{\circ}\right)$ & $\operatorname{Pr}\left({ }^{\circ}\right)$ & $\begin{array}{l}\text { ICC (range } \\
95 \% \mathrm{Cl})\end{array}$ \\
\hline HOA RMS $(\mu \mathrm{m})$ & $\begin{array}{l}0.23(0.13) \\
0.19(0.07 \text { to } 0.73)\end{array}$ & 0.04 & 0.09 & $\begin{array}{l}0.922(0.893 \\
\text { to } 0.945)\end{array}$ \\
\hline $\begin{array}{l}\text { Primary coma } \\
\text { RMS }(\mu \mathrm{m})\end{array}$ & $\begin{array}{l}0.12(0.09) \\
0.09(0.02 \text { to } 0.5 \mathrm{I})\end{array}$ & 0.03 & .06 & $\begin{array}{l}0.939(0.916 \\
\text { to } 0.957)\end{array}$ \\
\hline $\begin{array}{l}\text { Trefoil RMS } \\
(\mu \mathrm{m})\end{array}$ & $\begin{array}{l}0.13(0.09) \\
0.10(0.02 \text { to } 0.48)\end{array}$ & 0.03 & 0.06 & $\begin{array}{l}0.940(0.918 \\
\text { to } 0.957)\end{array}$ \\
\hline$Z_{4}{ }^{0}($ & $\begin{array}{l}0.06(0.09) \\
0.04(-0.12 \text { to } 0.44)\end{array}$ & 0.03 & .05 & $\begin{array}{l}0.954(0.936 \\
\text { to } 0.967)\end{array}$ \\
\hline $\begin{array}{l}\text { Secondary } \\
\text { astigmatism RMS } \\
(\mu \mathrm{m})\end{array}$ & $\begin{array}{l}0.04(0.04) \\
0.03(0.01 \text { to } 0.20)\end{array}$ & 0.02 & 0.03 & $\begin{array}{l}0.86 \mathrm{I}(0.808 \\
\text { to } 0.90 \mathrm{I})\end{array}$ \\
\hline $\begin{array}{l}\text { Quadrafoil RMS } \\
(\mu \mathrm{m})\end{array}$ & $\begin{array}{l}0.04(0.03) \\
0.03(0.01 \text { to } 0.16)\end{array}$ & 0.01 & 0.03 & $\begin{array}{l}0.805(0.73 \mathrm{I} \\
\text { to } 0.86 \mathrm{I})\end{array}$ \\
\hline
\end{tabular}

Abbreviations: $S_{w}$, within-subject standard deviation; $\mathrm{Pr}$, intrasession precision I.96 $\times \mathrm{S}_{w} ; \mathrm{Z}_{4}^{0}$, Zernike term corresponding to the primary spherical aberration; SD, standard deviation; ICC, intraclass correlation coefficient; HOA, higher order aberrations; RMS, root mean square.

sphere, $\mathrm{J}_{0}, \mathrm{~J}_{45}$, and B measurements with their $\mathrm{S}_{\mathrm{w}}$ associated were found $(-0.033 \leq r \leq 0.053, p \geq 0.064)$. A poor but statistically significant correlation was found between cylinder and its $\mathrm{S}_{\mathrm{w}}(r=-0.194, p=0.045)$. Concerning aberrometric data, moderate and significant positive correlations were found between the magnitude of the aberrometric parameters evaluated and their $\mathrm{S}_{\mathrm{w}}(r \geq 0.446, p<0.001)$. No significant correlations were found between the magnitude of sphere and cylinder and the $\mathrm{S}_{\mathrm{w}}$ corresponding to the different aberrometric parameters evaluated $(-0.171 \leq r \leq 0.131, p \geq 0.078)$. 
Table 3 Summary of correlations between different refractive and aberrometric parameters and their within-subject standard deviation $\left(\mathrm{S}_{\mathrm{w}}\right)$ associated

\begin{tabular}{|c|c|c|}
\hline & $\begin{array}{l}\text { Correlation } \\
\text { Pearson } \\
\text { coefficient }\end{array}$ & $P$-value \\
\hline Sphere with $\mathrm{S}_{\mathrm{w}}$ & 0.053 & 0.589 \\
\hline Cylinder with $\mathrm{S}_{\mathrm{w}}$ & -0.194 & 0.045 \\
\hline $\mathrm{J}_{0}$ with $\mathrm{S}_{\mathrm{w}}$ & -0.033 & 0.739 \\
\hline $\mathrm{J}_{45}$ with $\mathrm{S}_{\mathrm{w}}$ & 0.024 & 0.807 \\
\hline B with $S_{w}$ & 0.180 & 0.064 \\
\hline HOA RMS with $\mathrm{S}_{w}$ & 0.469 & $<0.001$ \\
\hline Primary coma RMS with $S_{w}$ & 0.588 & $<0.001$ \\
\hline Trefoil RMS with $\mathrm{S}_{\mathrm{w}}$ & 0.449 & $<0.001$ \\
\hline $\mathrm{Z}_{4}{ }^{0}$ with $\mathrm{S}_{\mathrm{w}}$ & 0.506 & $<0.001$ \\
\hline Secondary astigmatism RMS with $\mathrm{S}_{\mathrm{w}}$ & 0.446 & $<0.001$ \\
\hline Quadrafoil RMS with $S_{w}$ & 0.554 & $<0.001$ \\
\hline
\end{tabular}

Abbreviations: $S_{w}$, within-subject standard deviation; $J_{0}$ and $J_{45}$, power vector components; $B$, overall blurring strength; $Z_{4}^{0}$, Zernike term corresponding to the primary spherical aberration; HOA, higher order aberrations; RMS, root mean square.

\section{Discussion}

New multidiagnostic devices combining Scheimpflug imaging with other technologies are very useful in clinical setting for obtaining a complete analysis of the anatomical and optical properties of different anterior segment structures. ${ }^{1}$ One of the main advantages of these devices is that the measurement procedure is not time- and space-consuming in spite of measuring a very large number of parameters. ${ }^{1}$ Likewise, the consistency and reliability of the measurements obtained are high. ${ }^{1}$ Recently, a new multidiagnostic equipment has been developed and commercially released, the VX120 system, that combines several technologies to obtain not only refractive, aberrometric, and corneal topographic measurements in 1 measurement session but also IOP and a great variety of anatomical parameters. In the present study, we have evaluated the consistency of refractive and ocular aberrometric measurements provided by this new device in a normal healthy population. To our knowledge, this is the first scientific study evaluating the reliability of measurements obtained using this new multidiagnostic system.

The intrasession repeatability of the refractive measurements was excellent, with $\mathrm{S}_{\mathrm{w}}$ and intrasubject precision below 0.12 and $0.20 \mathrm{D}$, respectively, and ICC values of 0.947 or better. These results are similar and even better than those reported for other modalities of aberrometers. ${ }^{13-16} \mathrm{~S}_{\mathrm{w}}$ values of $0.18,0.20,0.10$, and $0.20 \mathrm{D}$ have been reported with a ray tracing aberrometer (iTrace; Tracey Technologies) for sphere, $\mathrm{J}_{0}, \mathrm{~J}_{45}$, and spherical equivalent also in a sample of healthy eyes, respectively. ${ }^{16} \mathrm{~S}_{\mathrm{w}}$ values of 0.25 and $0.08 \mathrm{D}$ have been reported for the magnitude of sphere and cylinder measured with a new generation Hartmann-Shack aberrometer (iDesign; Abbott Medical Optics). ${ }^{14}$ Segura et al ${ }^{15}$ calculated the ICC for 3 repeated refractive measurements in healthy eyes obtained with the WAM-5500 autorefractometer (Grand Seiko Co.) and a ray tracing aberrometer (iTrace; Tracey Technologies) and found values of 0.999 and 0.904 for sphere and cylinder with the autorefractometer and values of 0.998 and 0.939 with the aberrometer. Therefore, the multidiagnostic equipment evaluated was able to provide in our series consistent measurements of refraction. Furthermore, the variability of consecutive measurements $\left(\mathrm{S}_{\mathrm{w}}\right)$ of refraction was not correlated with the magnitude of measurements. This means that the consistency of refractive measurements in high myopes was as good as in low or moderate myopes, hyperopes, or emmetropes.

Concerning ocular aberrometric measurements, high levels of intrasession repeatability were also found, with $\mathrm{S}_{\mathrm{w}}$ and intrasubject precision values below 0.05 and $0.10 \mu \mathrm{m}$, respectively, for all aberrometric parameters evaluated. Additionally, ICC values were over 0.90 , except for secondary astigmatism ( $\mathrm{ICC}=0.861)$ and quadrafoil $\mathrm{RMS}(\mathrm{ICC}=0.805)$. These outcomes are better than those reported for other types of aberrometers. ${ }^{4,14,17}$ Prakash et $\mathrm{al}^{14}$ found with a new generation Hartmann-Shack aberrometer $\mathrm{S}_{\mathrm{w}}$ values of $0.18,0.05$, 0.06 , and $0.06 \mu \mathrm{m}$ for consecutive repeated measures of HOA RMS, primary coma RMS, trefoil RMS, and the Zernike term corresponding to primary spherical aberration ( $6 \mathrm{~mm}$ pupil), respectively. López-Miguel et $\mathrm{al}^{4}$ found ICC values of $>0.87$ for repeated measurements of ocular aberrations with a device combining Hartmann-Shack aberrometry and Placido disk corneal topography, except for primary coma $(\mathrm{ICC}=0.75)$ and third-order aberration RMS (ICC $=0.72 ; 6 \mathrm{~mm}$ pupil). Therefore, the multidiagnostic device evaluated was able to provide consistent measurements of ocular aberrations in healthy eyes. The magnitude of the aberrometric parameters evaluated was significantly lower than the precision values $\left(1.96 \times \mathrm{S}_{\mathrm{w}}\right)$ or intrasession repeatability coefficients $\left(2.77 \times \mathrm{S}_{\mathrm{w}}\right)$ associated with them, which suggests that this device is capable of providing useful measures for performing truly successful wavefront-guided laser procedures. ${ }^{9}$

Moderate and statistically significant positive correlations were found among the magnitude of the aberrometric parameters evaluated and the $\mathrm{S}_{\mathrm{w}}$ values associated with them. This means that the consistency of aberrometric measurements may be somewhat more limited in highly aberrated eyes. This is consistent with the outcome reported in another study evaluating the consistency of internal aber- 
rations measured with another integrated system combining a Hartmann-Shack aberrometer and a Placido disk corneal topographer. ${ }^{3}$ In that study, the authors found that the consistency of some internal aberrometric measurements was limited by the level of aberration. ${ }^{3}$ In our series, the consistency of aberrometric measurements was within acceptable levels in all cases in spite of this moderate correlation between aberration magnitude and $\mathrm{S}_{\mathrm{w}}$. Future studies should confirm if these same acceptable levels of consistency of aberrometric measurements are observed in highly aberrated eyes.

The results of this study have only demonstrated that the multidiagnostic platform evaluated is able to provide consistent measurements of refraction, which is crucial for an instrument to be used in clinical practice. Future studies are being performed to demonstrate the interchangeability of the objective measurement of refraction provided by this device and the subjective measurement. Likewise, the interchangeability of this device with other autorefractometers and aberrometers should also be evaluated in future studies. Finally, the evaluation of consistency of refractive and aberrometric measurements should also be done in aberrated eyes, such as keratoconus and postsurgical eyes.

\section{Conclusion}

The new multidiagnostic device evaluated is able to provide consistent measurements of refraction and ocular aberrations in healthy eyes. The consistency of refractive measurements is not dependent on the magnitude of the refractive error, with the same precision ability for moderate to high myopic eyes and for hyperopes. The intrasession repeatability of aberrometric measurements is high in a healthy normal population. Future studies should be conducted to confirm if this level of intrasession repeatability for ocular aberrations is also observed in highly aberrated eyes, such as keratoconus.

\section{Disclosure}

The authors report no conflicts of interest in this work.

\section{References}

1. Piñero DP. Technologies for anatomical and geometric characterization of the corneal structure and anterior segment: a review. Semin Ophthalmol. 2015;30(3):161-170.
2. Asgari S, Hashemi H, Jafarzadehpur E, Mohamadi A, Rezvan F, Fotouhi A. OPD-Scan III: a repeatability and inter-device agreement study of a multifunctional device in emmetropia, ametropia, and keratoconus. Int Ophthalmol. 2016;36(5):697-705.

3. Piñero DP, Juan JT, Alió JL. Intrasubject repeatability of internal aberrometry obtained with a new integrated aberrometer. $J$ Refract Surg. 2011;27(7):509-517.

4. López-Miguel A, Martínez-Almeida L, González-García MJ, CocoMartín MB, Sobrado-Calvo P, Maldonado MJ. Precision of higher-order aberration measurements with a new Placido-disk topographer and Hartmann-Shack wavefront sensor. J Cataract Refract Surg. 2013; 39(2):242-249.

5. Cerviño A, Dominguez-Vicent A, Ferrer-Blasco T, García-Lázaro S, Albarrán-Diego C. Intrasubject repeatability of corneal power, thickness, and wavefront aberrations with a new version of a dual rotating Scheimpflug-Placido system. J Cataract Refract Surg. 2015;41(1):186-192.

6. Hernández-Camarena JC, Chirinos-Saldaña P, Navas A, et al. Repeatability, reproducibility, and agreement between three different Scheimpflug systems in measuring corneal and anterior segment biometry. J Refract Surg. 2014;30(9):616-621.

7. Bayhan HA, Aslan Bayhan S, Muhafiz E, Can I. Repeatability of aberrometric measurements in normal and keratoconus eyes using a new Scheimpflug-Placido topographer. J Cataract Refract Surg. 2014; 40(2):269-275.

8. Aramberri J, Araiz L, Garcia A, et al. Dual versus single Scheimpflug camera for anterior segment analysis: precision and agreement. J Cataract Refract Surg. 2012;38(11):1934-1949.

9. López-Miguel A, Maldonado MJ, Belzunce A, Barrio-Barrio J, CocoMartín MB, Nieto JC. Precision of a commercial Hartmann-Shack aberrometer: limits of total wavefront laser vision correction. $\mathrm{Am} \mathrm{J}$ Ophthalmol. 2012;154(5):799.e-807.e.

10. Shneor E, Millodot M, Avraham O, Amar S, Gordon-Shaag A. Clinical evaluation of the L80 autorefractometer. Clin Exp Optom. 2012; 95(1):66-71.

11. Piñero DP, López-Navarro A, Cabezos I, de Fez D, Caballero MT, Camps VJ. Corneal topographic and aberrometric measurements obtained with a multidiagnostic device in healthy eyes: intrasession repeatability. J Ophthalmol. 2017;2017:2149145.

12. Thibos LN, Horner D. Power vector analysis of the optical outcomes of refractive surgery. J Cataract Refract Surg. 2001;27(1):80-85.

13. Gabriel C, Klaproth OK, Titke C, Baumeister M, Bühren J, Kohnen T. Repeatability of topographic and aberrometric measurements at different accommodative states using a combined topographer and open-view aberrometer. J Cataract Refract Surg. 2015;41(4):806-811.

14. Prakash G, Jhanji V, Srivastava D, et al. Single session, intra-observer repeatability of an advanced new generation Hartmann-Shack aberrometer in refractive surgery candidates. JOphthalmic Vis Res. 2015;10(4):498-501.

15. Segura F, Sanchez-Cano A, Lopez de la Fuente C, Fuentes-Broto L, Pinilla I. Evaluation of patient visual comfort and repeatability of refractive values in non-presbyopic healthy eyes. Int J Ophthalmol. 2015;8(5): 1031-1036.

16. Piñero DP, Sánchez-Pérez PJ, Alió JL. Repeatability of measurements obtained with a ray tracing aberrometer. Optom Vis Sci. 2011;88(9): 1099-1105.

17. Otero C, Vilaseca M, Arjona M, Martínez-Roda JA, Pujol J. Repeatability of aberrometric measurements with a new instrument for visión analysis based on adaptive optics. J Refract Surg. 2015;31(3):188-194. 


\section{Publish your work in this journal}

Clinical Optometry is an international, peer-reviewed, open access journal publishing original research, basic science, clinical and epidemiological studies, reviews and evaluations on clinical optometry. All aspects of patient care are addressed within the journal as well as the practice of optometry including economic and business analyses. Basic and clinical

Submit your manuscript here: https://www.dovepress.com/clinical-optometry-journal research papers are published that cover all aspects of optics, refraction and its application to the theory and practice of optometry. The manuscript management system is completely online and includes a very quick and fair peer-review system, which is all easy to use. Visit http://www.dovepress. com/testimonials.php to read real quotes from published authors. 